\title{
L-Band Radiometers Measuring Salinity From Space: Atmospheric Propagation Effects
}

Skou, Niels; Hofman-Bang, Dorthe

Published in:

I E E E Transactions on Geoscience and Remote Sensing

Link to article, DOI:

10.1109/TGRS.2005.856115

Publication date:

2005

Document Version

Publisher's PDF, also known as Version of record

Link back to DTU Orbit

Citation (APA):

Skou, N., \& Hofman-Bang, D. (2005). L-Band Radiometers Measuring Salinity From Space: Atmospheric Propagation Effects. I E E E Transactions on Geoscience and Remote Sensing, 43(10), 2210-2217. https://doi.org/10.1109/TGRS.2005.856115

\section{General rights}

Copyright and moral rights for the publications made accessible in the public portal are retained by the authors and/or other copyright owners and it is a condition of accessing publications that users recognise and abide by the legal requirements associated with these rights.

- Users may download and print one copy of any publication from the public portal for the purpose of private study or research.

- You may not further distribute the material or use it for any profit-making activity or commercial gain

- You may freely distribute the URL identifying the publication in the public portal 


\title{
L-Band Radiometers Measuring Salinity From Space: Atmospheric Propagation Effects
}

\author{
Niels Skou, Fellow, IEEE, and Dorthe Hoffman-Bang
}

\begin{abstract}
Microwave radiometers can measure sea surface salinity from space using L-band frequencies around $1.4 \mathrm{GHz}$. However, requirements to the accuracy of the measurements, in order to be satisfactory for the user, are so stringent that the influence of the intervening atmosphere cannot be neglected. The present paper will describe and quantify the effect of losses in the atmosphere caused by oxygen, water vapor, clouds, and rain, and indicate possible correction actions to be taken.
\end{abstract}

Index Terms-Atmospheric propagation, L-band radiometer, ocean salinity, oxygen absorption.

\section{INTRODUCTION}

$\mathbf{S}$ PACEBORNE L-band radiometry at the protected band (1400-1427 MHz) enables global measurements of the important geophysical parameters sea surface salinity and soil moisture. Despite the fact that this has been known for decades, and that the importance of such measurements also has been realized for many years, no space systems have been available for the task. The reason has been lack of proper technology for achieving reasonable ground resolution considering the relatively low microwave frequency to be used. However, this situation has changed lately, and now three very different L-band missions are under development. The first to be launched (in 2007) is the European Soil Moisture and Ocean Salinity (SMOS) satellite that circumvents the ground resolution problem by using an advanced two-dimensional synthetic aperture radiometer. Following that, two real aperture U.S. systems, taking advantage of advanced antenna reflector technology, will be launched. One, the Acquarius, is a pushbroom system, the other, Hydros, is a more classical scanner.

No matter which imaging principle is used, it must, however, be recalled that what the radiometer system measures is the brightness temperature impinging on the antenna, while what is wanted is the brightness temperature as emitted from the Earth's surface. One (amongst several) effect that renders these two not equal is the atmospheric loss, and important work on this subject has been reported in [1]. The present paper will go into somewhat more detail and deal with effects of oxygen, water vapor, clouds, and rain. Also worth mentioning here is the fact that not only the atmosphere influences the received brightness temperature, but also the ionosphere. This is not the subject for the present paper, but reference can be made to [2] and [3].

Manuscript received January 18, 2005; revised July 13, 2005. This work was supported by the European Space Agency as part of the preparations of the SMOS Mission.

The authors are with the Oersted DTU, Electromagnetic Systems Section, Technical University of Denmark, DK-2800 Lyngby, Denmark (e-mail: ns@oersted.dtu.dk).

Digital Object Identifier 10.1109/TGRS.2005.856115
The most stringent requirements to the radiometer system are imposed by the salinity observations, and the present paper is dealing with aspects of this subject. The brightness temperature sensitivity to salinity changes is at best (warm oceans) approaching $1 \mathrm{~K} / \mathrm{psu}$ (practical salinity unit; 1 psu is in effect equal to one part per thousand). At the same time, users require salinity to be measured to some 0.1 -psu resolution and accuracy. This means that we have to make radiometric measurements with an accuracy better than $0.1 \mathrm{~K}$ which is not easy, and at the same time correct for unwanted disturbances with an accuracy also below $0.1 \mathrm{~K}$. Accordingly, we cannot just assume that the atmosphere is transparent at L-band despite the relatively low frequency.

The present paper will investigate several aspects of atmospheric losses at L-band, and in several instances reference will be made to the SMOS mission. The investigations, however, apply to any spaceborne L-band mission.

\section{BACKGROUND}

\section{A. Measured Brightness Temperature}

The task of the SMOS radiometer is to measure the brightness temperature of the sea surface, but this is not possible directly. Instead the radiometer measures a sum of radiation from different sources propagated through the atmosphere. The brightness temperature, which the radiometer actually measures, can be expressed mathematically as shown in (1)

$$
\begin{aligned}
T_{\mathrm{B}, \text { measured }}=T_{\mathrm{B}, \text { sea }} e^{-\tau}+T_{\text {upwelling }} & \\
& +\Gamma T_{\text {downwelling }} e^{-\tau}+\Gamma T_{\text {space }} e^{-2 \tau}
\end{aligned}
$$

where $T_{\mathrm{B}, \text { sea }}$ is the brightness temperature emitted by the sea surface, $T_{\text {upwelling }}$ is the brightness temperature self-emitted by the atmosphere in the upward direction, $T_{\text {downwelling }}$ is the brightness temperature self-emitted by the atmosphere in the downward direction, $T_{\text {space }}$ is the cosmic background radiation, $\Gamma$ is the surface reflection coefficient, and $e^{-\tau}$ expresses the attenuation through the atmosphere. The cosmic radiation is included in (1) for completeness, but will not be treated further in this paper. In the following, the magnitude of the atmospheric effects will be quantified, and it will be investigated how to compensate for these factors. The goal is to be able to calculate the actual sea surface brightness temperature from the brightness temperature measured by the radiometer.

As can be seen from the radiative transfer equation, there are two types of processes in the atmosphere, which will interfere with electromagnetic wave propagation: absorption and emission. Absorption and emission are caused by the following:

- gases in the atmosphere;

- clouds in the atmosphere;

- precipitation in the atmosphere. 
Molecular absorption and emission in the microwave region is due to the presence of oxygen and water vapor. These substances have strong absorption lines at specific microwave frequencies, but due to different line broadening mechanisms, these have wings responsible for effects throughout the spectrum, including L-band. There are also other atmospheric gases and pollutants, which have absorption lines in the microwave spectrum. But their relative concentrations at sea level are very small, so their contributions to the microwave gaseous absorption are negligible in comparison with the contributions from oxygen and water vapor [4].

The total effect in the atmosphere can be expressed as a sum of the effects from each of the individual factors as a function of the height $z$ (kilometers).

\section{B. Standard Atmosphere}

The absorption and emission in the atmosphere are dependent on the meteorological conditions in the atmosphere, which again depend strongly on altitude. The pressure and density of the atmosphere decreases approximately exponentially with altitude, while the temperature variation is more complex. The 1962 U.S. Standard Atmosphere is a general description of the vertical structure of the Earth's atmosphere. For the present investigations a simplified, so-called abridged version is sufficient. This is due to the fact that we are interested in magnitudes and tendencies, and not so much in precise values (which of course eventually are required for data correction; see Section VII). For most microwave remote sensing of the Earth, and certainly at L-band, it is the lower part of the atmosphere that is of greatest interest, since the major part of the atmospheric mass is found here ( $99 \%$ of the mass is found below some $30 \mathrm{~km}$ of altitude). Therefore, for computational purposes, it is only the lower 30 $\mathrm{km}$ of the atmosphere that need to be taken into consideration.

For the lower $30 \mathrm{~km}$ of the atmosphere, simple expressions have been developed from the abridged 1962 U.S. Standard Atmosphere [5]. The properties of interest are the temperature profile, the pressure profile, and the water vapor density profile.

The temperature profile can be expressed as

$$
T(z)= \begin{cases}T_{0}-6.5 z, & 0 \mathrm{~km} \leq z \leq 11 \mathrm{~km} \\ T(11), & 11 \mathrm{~km} \leq z \leq 20 \mathrm{~km} \\ T(11)+(z-20), & 20 \mathrm{~km} \leq z \leq 32 \mathrm{~km}\end{cases}
$$

where $z$ is the altitude in kilometers, $T_{0}$ is the temperature in Kelvin at sea level, and $T(11)$ is the atmospheric temperature at $11 \mathrm{~km}$.

The pressure profile can be described as

$$
P(z)=P_{0} e^{-z / 7.7 \mathrm{~km}}[\mathrm{mbar}]
$$

where $P_{0}$ is the pressure at sea level.

The amount of water vapor in the atmosphere is dependent on several meteorological parameters, but is especially dependent on the temperature of the atmosphere. At sea level, the water vapor density can vary from $0.1 \mathrm{~g} / \mathrm{m}^{3}$ in very cold dry climates to $30 \mathrm{~g} / \mathrm{m}^{3}$ in very hot and humid climates. The altitude water vapor density function can be written as

$$
\rho_{v}(z)=\rho_{0} e^{-z / H}\left[\mathrm{~g} / \mathrm{m}^{3}\right]
$$

TABLE I

EMITTED BRIGHTNESS TEMPERATURES, EMISSIVITIES, AND REFLECTION COEFFICIENTS USED FOR THE PRESENT INVESTIGATIONS

\begin{tabular}{l|c|c|c}
\hline Incidence angle/polarization & $\mathrm{T}_{\mathrm{B}, \mathrm{sea}}$ & $\varepsilon$ & $\Gamma$ \\
\hline $0^{\circ}$ & $96.6 \mathrm{~K}$ & 0.3295 & 0.6705 \\
\hline $55^{\circ}, \mathrm{V}$-polarization & $144.6 \mathrm{~K}$ & 0.4933 & 0.5067 \\
\hline $55^{\circ}, \mathrm{H}$-polarization & $62.5 \mathrm{~K}$ & 0.2132 & 0.7868 \\
\hline
\end{tabular}

where $z$ is the altitude in kilometers, $\rho_{0}$ is the surface value of the water vapor density, and $H$ is the scale height, which is typically chosen to be between 2 and $2.5 \mathrm{~km}$.

Because the properties of the atmosphere change as a function of the altitude, this has to be taken into due consideration when calculating the attenuation and emission of the atmosphere. For all calculations carried out throughout this paper, the lower 30 $\mathrm{km}$ of the atmosphere have been divided into 600 layers of each $50 \mathrm{~m}$. For each layer, the properties of the atmosphere contained in the specific layer have been calculated.

\section{Brightness Temperature Emitted by the Sea Surface}

The brightness temperature $T_{\mathrm{B} \text {,sea }}$ emitted by the sea surface is dependent on many parameters such as: frequency, temperature of the surface, salinity, incidence angle, and surface roughness. The variations of the sea surface brightness temperature are not the subject for the present investigations, and some simplifying assumptions are made. First of all, we limit the situation to include only two incidence angles: $0^{\circ}$ and $55^{\circ}$. For $55^{\circ}$ incidence angle both vertical and horizontal polarizations are considered. The brightness temperatures are calculated based on the Klein and Swift model [6] for a sea surface temperature of 293 $\mathrm{K}$, a salinity of $36 \mathrm{psu}$, and no wind-induced surface roughness. The brightness temperatures, the emissivities $(\varepsilon)$, and the reflection coefficients for the three situations are shown in Table I.

\section{ABSORPTION AND EMISSION DUE TO OXYGEN}

The oxygen molecules produce a family of absorption lines near $60 \mathrm{GHz}$, and an additional isolated line at $118.75 \mathrm{GHz}$.

A model for the absorption by oxygen for lower frequencies is described in [5]. For frequencies below $45 \mathrm{GHz}$, the contribution from the 118-GHz absorption line can be neglected, and only the contribution from the $60-\mathrm{GHz}$ complex must be considered. Then the absorption from oxygen at $f=1.4 \mathrm{GHz}$ can be written as

$$
\begin{aligned}
\kappa_{O_{2}}(f)= & 1.1 \cdot 10^{-2} f^{2}\left(\frac{P}{1013}\right)\left(\frac{300}{T}\right)^{2} \\
& \times \gamma\left(\frac{1}{\left(f-f_{0}\right)^{2}+\gamma^{2}}+\frac{1}{f^{2}+\gamma^{2}}\right)[\mathrm{dB} / \mathrm{km}]
\end{aligned}
$$

where $f$ is the frequency $(1.4 \mathrm{GHz}), f_{0}$ is the absorption line frequency $(60 \mathrm{GHz}), P$ is the pressure in millibars, $T$ is the temperature in Kelvin, and $\gamma$ is the line width parameter written as

$$
\gamma=\gamma_{0}\left(\frac{P}{1013}\right)\left(\frac{300}{T}\right)^{0.85}[\mathrm{GHz}]
$$


where $\gamma_{0}$ is the nonresonant line width, which is dependent on the pressure, and can be expressed as

$\gamma_{0}= \begin{cases}0.59, & P \geq 333 \mathrm{mbar} \\ 0.59\left(1+3.1 \cdot 10^{-3}(333-P)\right), & 25 \leq P \leq 333 \mathrm{mbar} \\ 1.18, & P \leq 25 \mathrm{mbar} .\end{cases}$

This well-known and easy-to-use model reflects the knowledge as of 1980 before oxygen line mixing was well established. Equation (7) is basically not correct, but in a way that has little effect here, since most of the absorption occurs at pressures above $333 \mathrm{mbar}$, and for the low frequency of $1.4 \mathrm{GHz},(5)$ and (6) can be used with a constant value for $\gamma_{0}$. Comparison with up-to-date models [7]-[10] shows excellent agreement at $1.4 \mathrm{GHz}$ (but deviates at higher frequencies).

Based on (5)-(7), the absorption in a layer of the atmosphere due to oxygen can be calculated for different temperatures and pressures, to be used in the following simulations.

The first to be calculated is the downwelling temperature. The downwelling radiation originates from self-emission in the downward direction of the atmosphere, and because the radiation is being reflected in the sea surface it contributes to the brightness temperature in the direction of the radiometer. To facilitate the calculation of the downwelling radiation, the atmosphere is divided into 50-m layers as described previously. A certain layer has an inbound signal from the previous layer. This signal is attenuated by the loss $L$ in the layer calculated by multiplying the previously calculated absorption coefficients with $50 \mathrm{~m}$ (layer thickness). To this is added the self-emission of the layer calculated from

$$
T_{\text {downwelling }}=T_{\text {phy }}\left(1-\frac{1}{L}\right),[K]
$$

where $T_{\text {phy }}$ is the physical temperature of the air in the layer. The result is the outbound radiation, which in turn is the inbound signal for the next layer. This process is continued through the $30 \mathrm{~km}$ of atmosphere being considered.

The downwelling signal is reflected in the sea surface using the reflection coefficient from Table I and added to the sea brightness temperature also found from Table I. Now start a process up through the atmosphere with loss and self-emission of the individual layers just as described above for the downwelling signal.

In order to find the resulting effect on the measured sea brightness temperature, a simulation has been carried out following the guidelines set forth above. In the simulation, the downwelling contribution, the atmospheric loss, and the atmospheric upwelling emission have been included for the lower 30 $\mathrm{km}$ of the atmosphere. The resulting error is the difference in degrees Kelvin between the calculated brightness temperature at the radiometer and the emitted brightness temperature of the sea.

The result is seen in Fig. 1 where the error due to oxygen in the atmosphere is shown as a function of the surface pressure for three different atmospheric temperatures at the surface.

The resulting error due to oxygen in the atmosphere increases with increasing surface pressure and with a decrease in the surface air temperature. At a normal surface pressure of $1013 \mathrm{mbar}$ and a surface air temperature of $290 \mathrm{~K}$, the resulting error is about $3.9 \mathrm{~K}$ for $0^{\circ}, 4.9 \mathrm{~K}$ for $55^{\circ}$ vertical $(\mathrm{V})$ polarization, and $7.9 \mathrm{~K}$ for $55^{\circ}$ horizontal $(\mathrm{H})$ polarization. This means that the

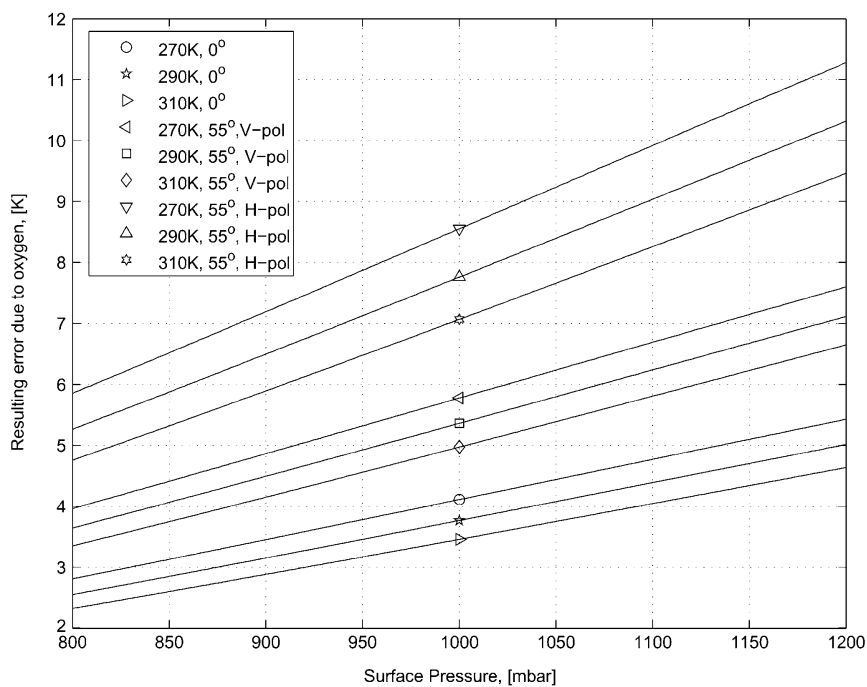

Fig. 1. Resulting difference between the brightness temperatures measured by the radiometer and the emitted sea surface brightness temperatures as a function of the surface pressure. The curves are shown for three different surface air temperatures and three different measurement cases.

TABLE II

SENSITIVITY OF THE RESUlting ERROR to CHANGES IN THE SURFACE PRESSURE AND Air Temperature. The SENSITIVITY to Air TEMPERATURE HAS BEEN CALCUlATED FOR A PRESSURE OF $1013 \mathrm{mbar}$, AND THE SENSITIVITY to Pressure Has BeEn Calculated for an AIR Temperature of $290 \mathrm{~K}$

\begin{tabular}{l|c|c}
\hline Measurement case & $\mathrm{mK} /{ }^{\circ} \mathrm{C}$ & $\mathrm{mK} / \mathrm{mbar}$ \\
\hline $0^{\circ}$ & -16.75 & 6.23 \\
\hline $55^{\circ}, \mathrm{V}$-pol & -14.75 & 8.62 \\
\hline $55^{\circ}, \mathrm{H}-$ pol & -37.75 & 12.76 \\
\hline
\end{tabular}

TABLE III

REQUIRED CHANGE IN THE INDIVIDUAL GEOPHYSICAL PARAMETERS CORRESPONDING TO A 0.1-K CHANGE IN THE RESUlTING ERROR

\begin{tabular}{l|c|c}
\hline Measurement case & ${ }^{\circ} \mathrm{C}$ & mbar \\
\hline $0^{\circ}$ & 5.97 & 16.05 \\
\hline $55^{\circ}, \mathrm{V}$-pol & 6.78 & 11.60 \\
\hline $55^{\circ}, \mathrm{H}$-pol & 2.65 & 7.84 \\
\hline
\end{tabular}

brightness temperature as measured by the radiometer is significantly larger than the brightness temperature at the sea surface and that the interference from oxygen in the atmosphere certainly has to be taken into consideration. In order to find out how dependent the resulting error is of the geophysical parameters, the slopes of the curves have been calculated, and the result can be seen in Table II. The temperature slope has been calculated for a surface pressure of $1013 \mathrm{mbar}$, and the pressure slope has been calculated for a surface air temperature of $290 \mathrm{~K}$. In Table III, the dependence is recalculated, so it shows how much the individual geophysical parameter can change before the resulting error changes by $0.1 \mathrm{~K}$.

It is clear that the $55^{\circ} \mathrm{H}$-polarization case is the most sensitive to variation in the geophysical parameters. Assuming an accuracy criterion of $0.1 \mathrm{~K}$, the strictest requirement in order to 
carry out a correction scheme $\left(55^{\circ}\right.$, H-polarization) is a temperature knowledge to within $2.7^{\circ} \mathrm{C}$ and a pressure knowledge to within 7.8 mbar.

\section{ABSORPTION AND EMISSION DUE TO WATER VAPOR}

In the microwave region, water vapor has rotational absorption lines at 22.235 and at $183.31 \mathrm{GHz}$. Furthermore, there are also some absorption lines above this region, which contributes to the microwave absorption spectrum. For calculation of the absorption at a frequency of $1.4 \mathrm{GHz}$, one can according to [5] group the contributions from the $183.31 \mathrm{GHz}$ and all the absorptions lines above in a residual term. The resulting absorption can then be written as a sum of the residual term $\kappa_{r}(f)$ and the contribution from the $22.235-\mathrm{GHz}$ absorption line $\kappa(f, 22)$

$$
\kappa_{H_{2} O}(f)=\kappa(f, 22)+\kappa_{r}(f)[\mathrm{dB} / \mathrm{km}] .
$$

The absorption coefficient for the $22.235-\mathrm{GHz}$ line can, according to [11, Sec. 2], be written as

$$
\begin{aligned}
\kappa(f, 22)=2 f^{2} \rho_{\nu} & \left(\frac{300}{T}\right)^{5 / 2} e^{-644 / T} \\
& \times\left(\frac{\gamma_{1}}{\left(494.4-f^{2}\right)^{2}+4 f^{2} \gamma_{1}^{2}}\right)[\mathrm{dB} / \mathrm{km}]
\end{aligned}
$$

where $f$ is the frequency $(1.4 \mathrm{GHz}), \rho_{\nu}$ is the density in grams per cubic meter, $T$ is the temperature in Kelvin, and $\gamma_{1}$ is the line width parameter given by

$\gamma_{1}=2.85\left(\frac{P}{1013}\right)\left(\frac{300}{T}\right)^{0.626}\left(1+0.018 \frac{\rho_{\nu} T}{P}\right)[\mathrm{GHz}]$

where $P$ is the atmospheric pressure in millibars.

The residual absorption coefficient can, according to [5], be written as

$$
\kappa_{r}(f)=2.4 \cdot 10^{-6} f^{2} \rho_{\nu}\left(\frac{300}{T}\right)^{3 / 2} \gamma_{1}[\mathrm{~dB} / \mathrm{km}] .
$$

Based on these equations, the absorption coefficient due to water vapor in the atmosphere is calculated for the relevant range of temperatures, pressures, and water vapor densities, to be used in the following simulations. The calculations follow the same procedure as outlined for oxygen in the previous section.

The resulting error due to the water vapor in the atmosphere is seen in Fig. 2 as a function of the surface pressure and in Fig. 3 as a function of the water vapor mass density at the surface. In both figures, the resulting error for each of the three measurement cases is shown for three different surface air temperatures. The resulting error increases with an increase in the surface pressure and with an increase in the surface water vapor mass density. When the surface air temperature increases the resulting error decreases.

If resulting errors below $0.1 \mathrm{~K}$ is assumed acceptable, it is seen from the two figures that for low to moderate mass densities the error due to water vapor is below the criterion. For an average case where $P_{0}=1013 \mathrm{mbar}, T_{0}=290 \mathrm{~K}$, and $\rho_{0}=7.5 \mathrm{~g} / \mathrm{m}^{3}$, the resulting errors are $0.025 \mathrm{~K}$ for $0^{\circ}, 0.032 \mathrm{~K}$ for $55^{\circ} \mathrm{V}$-polarization and $0.051 \mathrm{~K}$ for $55^{\circ} \mathrm{H}$-polarization, so for the average conditions the influence from water vapor can

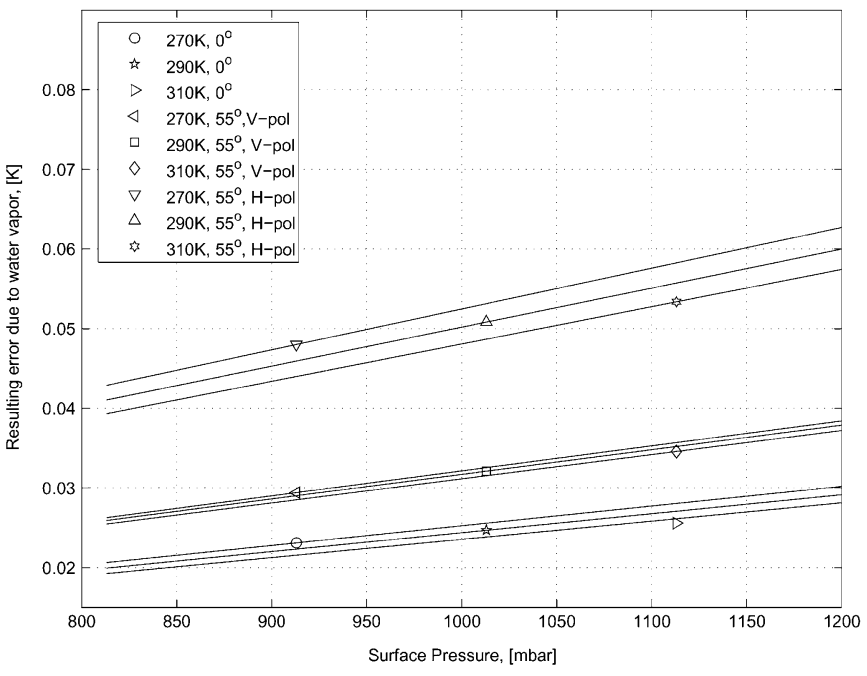

Fig. 2. Resulting difference between the brightness temperature measured by the radiometer and the emitted sea surface brightness temperature. The error is shown for each of the three measurement cases as a function of the surface pressure for three different surface air temperatures. The mass density of the water vapor at the surface has been set to a fixed value of $7.5 \mathrm{~g} / \mathrm{m}^{3}$.

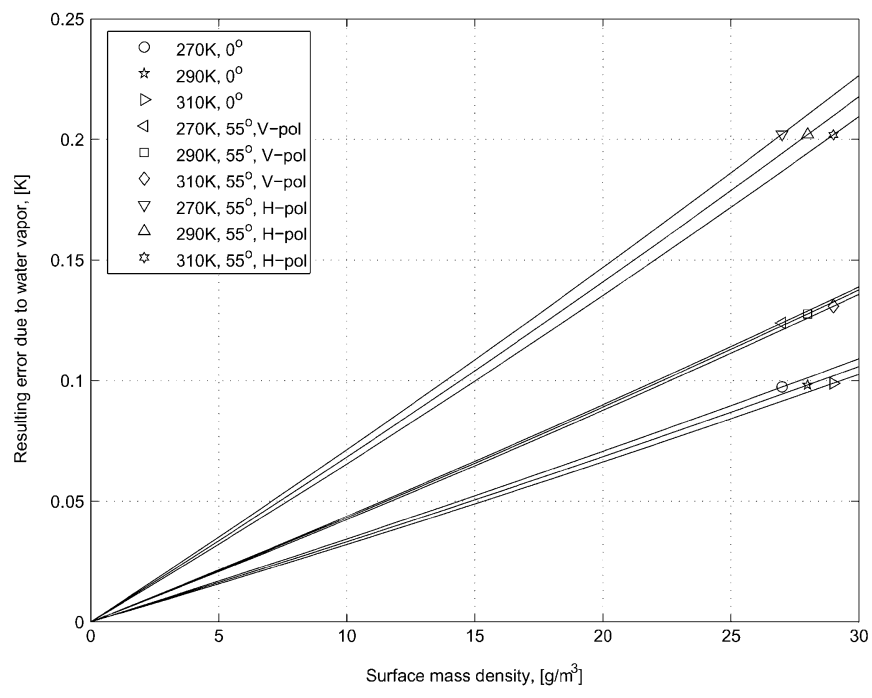

Fig. 3. Resulting difference between the brightness temperature measured by the radiometer and the emitted sea surface brightness temperature as a function of the surface mass density of the water vapor. The error is shown for each of the three measurement cases for three different surface air temperatures. The atmospheric surface pressure has been set to a fixed value of $1013 \mathrm{mbar}$.

be neglected. But when the mass density increases, the criterion is reached first for the measurement case of $55^{\circ}$ incidence angle and $\mathrm{H}$-polarization. For the average $P_{0}$ and $T_{0}$, the limit is reached for a mass density of $13.9 \mathrm{~g} / \mathrm{m}^{3}$. For the measurement case of $55^{\circ} \mathrm{V}$-polarization, the limit is reached for a mass density of $22.1 \mathrm{~g} / \mathrm{m}^{3}$, and finally for the zenith measurement case the limit is first reached for a mass density of $27.7 \mathrm{~g} / \mathrm{m}^{3}$, which does not occur very often.

In order to find out how sensitive the resulting error is to the value of the geophysical parameters, the dependence has been calculated, and the result can be seen in Table IV. In Table V, the dependence has been recalculated so that it is shown how much the individual geophysical parameters have to change in order for the resulting error to change by $0.1 \mathrm{~K}$. 
TABLE IV

SENSITIVITY OF THE RESULTING ERROR TO CHANGES IN THE GEOPHYSICAL PARAMETERs. For the CAlCulation the Following AVERAGE VAlues HAVE BEEN USED: $P 0=1013 \mathrm{mbar}, T_{0}=290 \mathrm{~K}$, AND $\rho_{0}=7.5 \mathrm{~g} / \mathrm{m}^{3}$

\begin{tabular}{l|c|c|c}
\hline & $\mathrm{mK} /\left(\mathrm{g} / \mathrm{m}^{3}\right)$ & $\mathrm{mK} /{ }^{\circ} \mathrm{C}$ & $\mathrm{mK} / \mathrm{mbar}$ \\
\hline $0^{\circ}$ & 3.2 & -0.05 & 0.0162 \\
\hline $55^{\circ}, \mathrm{V}$-pol & 4.4 & -0.03 & 0.0324 \\
\hline $55^{\circ}, \mathrm{H}$-pol & 6.8 & -0.11 & 0.0459 \\
\hline
\end{tabular}

TABLE V

REQUiRED CHANGE IN THE INDIVIDUAL GEOPHYSICAL PARAMETERS CORRESPONDING TO A 0.1-K CHANGE IN THE RESUlTING ERROR

\begin{tabular}{l|c|c|c}
\hline & $\mathrm{g} / \mathrm{m}^{3}$ & ${ }^{\circ} \mathrm{C}$ & $\mathrm{mbar}$ \\
\hline $0^{\circ}$ & 31.25 & 2000 & 6172 \\
\hline $55^{\circ}, \mathrm{V}$-pol & 22.73 & 3333 & 3086 \\
\hline $55^{\circ}, \mathrm{H}-$ pol & 14.71 & 909 & 2178 \\
\hline
\end{tabular}

It is obvious that in most cases the water vapor influence on the measured brightness temperature can be neglected, and that only a modest knowledge of geophysical parameters is required for water vapor corrections in extremely humid conditions.

\section{Cloud Effects}

When electromagnetic waves interacts with particles such as those in snow, clouds, fog, and rain it involves in principle both absorption and scattering. But if only drops, which have a diameter much smaller than the wavelength, are considered-which is the case for the combination clouds $/ 1.4 \mathrm{GHz}$ - then scattering is unimportant, and only absorption need to be considered.

Clouds are very complex and consists of water either in liquid or in frozen form. The amount of water and the phase of the water in the cloud depend on the temperature and the water vapor density in the cloud. The water content of a cloud is according to [5] typically less than $1 \mathrm{~g} / \mathrm{m}^{3}$. But due to the complexity of clouds we have to use standard models for the properties of different kinds of clouds. In Table VI, some of the properties of six standard cloud models are shown. The clouds are described by their cloud base, the top of the cloud, the mass density of the liquid water in the cloud, and the principal composition of the cloud. It has to be understood that these six standard cloud models are examples. Other clouds may exist, but the six standard models are believed to duly represent typical conditions.

When talking about the phases of the water in the clouds the phenomenon called supercooling has to be considered. Supercooling is a normally occurring phenomenon in the atmosphere and concerns the fact that clouds composed of water droplets can stay liquid at temperatures well below $273{ }^{\circ} \mathrm{C}$, and even at temperatures below $243 \mathrm{~K}$. At temperatures below about $233{ }^{\circ} \mathrm{C}$, however, all cloud droplets will freeze very quickly [13].
TABLE VI

PROPERTIES OF STANDARD ClOUd MOdEls [12]

\begin{tabular}{l|c|c|c|c}
\hline Descriptive cloud name & $\begin{array}{l}\text { Cloud } \\
\text { base, }[\mathrm{m}]\end{array}$ & $\begin{array}{l}\text { Height } \\
\text { top, }[\mathrm{m}]\end{array}$ & $\begin{array}{c}\text { Mass density } \\
\text { liquid } \mathrm{H}_{2} \mathrm{O},\left(\mathrm{g} / \mathrm{m}^{3}\right)\end{array}$ & $\begin{array}{l}\text { Principal } \\
\text { composition }\end{array}$ \\
\hline Cirrostratus, mid-lat & 5000 & 7000 & 0.10 & Ice \\
\hline Low-lying stratus & 500 & 1000 & 0.25 & Water \\
\hline Fog layer & 0 & 50 & 0.15 & Water \\
\hline Haze layer & 0 & 1500 & 0.001 & Water \\
\hline Fair-weather cumulus & 500 & 1000 & 0.50 & Water \\
\hline Cumulus congestus & 1600 & 2000 & 0.80 & Water \\
\hline
\end{tabular}

The attenuation of electromagnetic waves due to the presence of clouds is dependent on the water content of the cloud, the principal composition of the cloud, and furthermore also on the physical temperature of the cloud. The water content of the cloud or the mass density of the liquid water $m_{\nu}$ is equal to the total volume occupied by the particles per unit volume $V_{p}$ multiplied by the density of water, which is $10^{6} \mathrm{~g} / \mathrm{m}^{3}$.

According to [5], the volume absorption coefficient for clouds can be approximated as the cloud volume extinction coefficient $\kappa_{\text {ec }}$ and can be written as

$$
\kappa_{\mathrm{ec}}=\kappa_{1} m_{v}[\mathrm{~dB} / \mathrm{km}]
$$

where $\kappa_{1}$ is the attenuation coefficient in decibels per kilomter per gram per cubic meter, and $m_{v}$ is the mass density of the water in the cloud. Two empirical functions have been developed in [14], one for the attenuation coefficient of water clouds and fog and one for the attenuation coefficient of ice clouds, as in (14), shown at the bottom of the page, where $f$ is the frequency in gigahertz, and $T$ is the temperature of the cloud (in degrees Celsius).

Based on these equations, the absorption coefficient due to clouds is calculated for the relevant range of temperatures, and mass density of the cloud liquid water, to be used in the following simulations. The calculations follow the same procedure as outlined in the previous sections, but only considering the relevant altitude range in which the clouds are found. No absorption and emission takes place between the sea surface and the cloud base nor from the cloud top and upward.

In Fig. 4, the resulting error due to loss and self-radiation of clouds in the atmosphere is shown as a function of the surface air temperature for the six different types of clouds. For clarity of the figure only the nadir looking case is shown. From the figure, it can be seen that practically no values of the resulting errors exceeds the accuracy criteria of $0.1 \mathrm{~K}$.

It is noted that the ice cloud signature only spans a limited temperature range. This is due to the fact that the model used only is valid in this limited range. However, is can safely be assumed that the ice absorption stays at very low values also for lower temperatures.

The conclusion of the investigation of the atmospheric loss due to absorption in clouds is that in general the clouds do not

$$
\kappa_{1}= \begin{cases}f^{1.95} \exp \left(-6.866\left(1+4.5 \cdot 10^{-3} T\right)\right), & \text { for water clouds and fog } \\ f^{1.006} \exp \left(-8.261\left(1-1.767 \cdot 10^{-2} T-4.374 \cdot 10^{-4} T^{2}\right)\right) & \text { for ice clouds }\end{cases}
$$




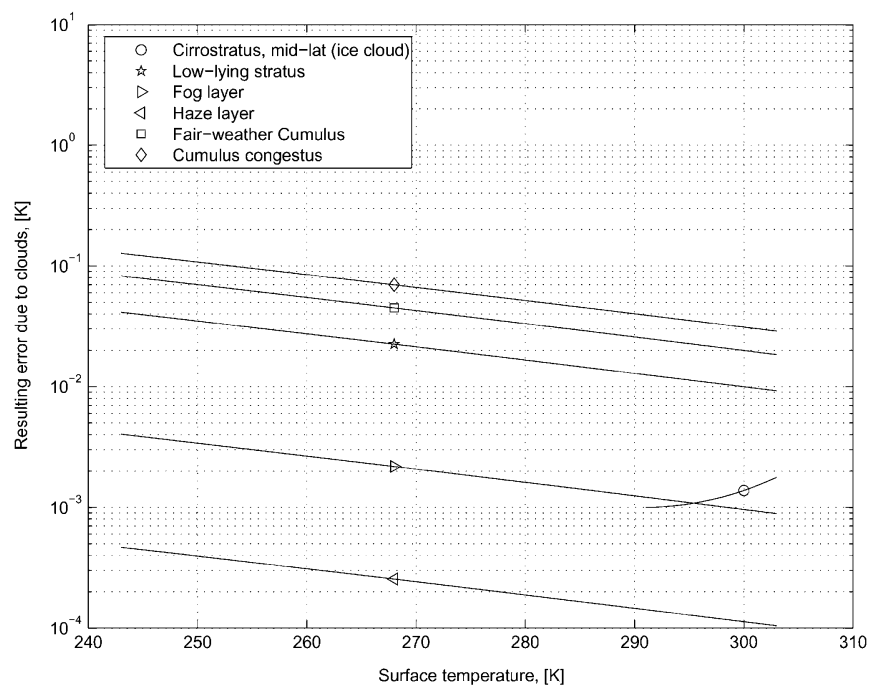

Fig. 4. Resulting difference between the brightness temperature measured by the radiometer and the emitted sea surface brightness temperature. Only the nadir looking case is considered. The error is shown as a function of the physical surface air temperature for six different cloud types. The properties of each of the clouds are given in Table VI. The cirrostratus cloud is the only cloud that contains ice; the rest contain water.

have a significant influence on remote sensing of the sea surface brightness temperature at $1.4 \mathrm{GHz}$.

\section{RAIN EFFECTS}

Individual hydrometers such as rain, hail, and snow particles both absorb and scatter an incident electromagnetic signal. In this paper, only the interaction with rain will be investigated because the attenuation due to snow and hail is low in comparison with the attenuation due to rain. Raindrops are typically two orders of magnitude larger in diameter than cloud droplets. Measurements of the raindrop size spectra shows large variations for the same location, rain type, and rain rate [4]. This implies that the attenuation and scattering properties of rain will also vary. For rain, the validity of the Raleigh approximation is limited to rainfall rates of less than $10 \mathrm{~mm} / \mathrm{h}$ in the microwave range. Therefore, Mie scattering should be used for computing the absorption and scattering in rain volumes even at the low microwave frequencies [5]. When describing the interaction between rain and electromagnetic waves, knowledge about the drop size distribution is required. If it is assumed that the drops are distributed throughout the volume as a Poisson distribution, it allows one to compute the attenuation and scattering cross section as values per unit volume [4].

In [15] an extensive set of tables of extinction properties of rain is presented. The table for $1.4 \mathrm{GHz}$ includes extinction, absorption, and scattering coefficients for eight rain rates from $0.25-150 \mathrm{~mm} / \mathrm{h}$. Absorption is practically equal to extinction for all realistic rain rates (at least up to $100 \mathrm{~mm} / \mathrm{h}$ ), due to the L-band wavelength being much larger than rain drop diameters, and thus the scattering component is relatively small. Hence, we shall in the following not distinguish between absorption and extinction (emission relies on absorption alone) and use the term attenuation. The attenuation coefficient found from [15] is shown in Fig. 5 as a function of the rain rate. As expected, the attenuation of the electromagnetic waves due to the presence of rain in the atmosphere increases with the rain rate.

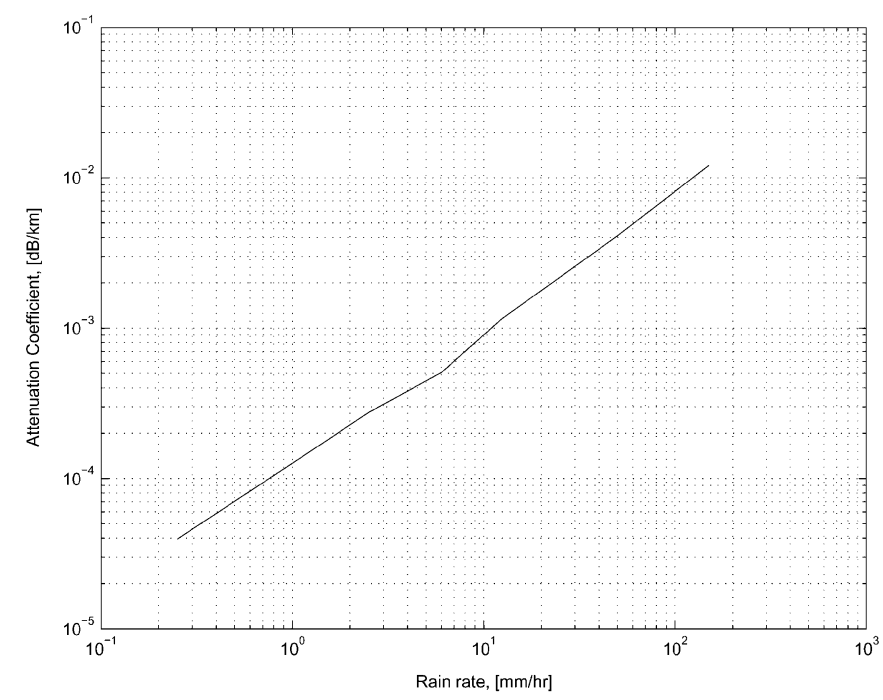

Fig. 5. Attenuation coefficient versus rain rate for a surface temperature of $293 \mathrm{~K}$.

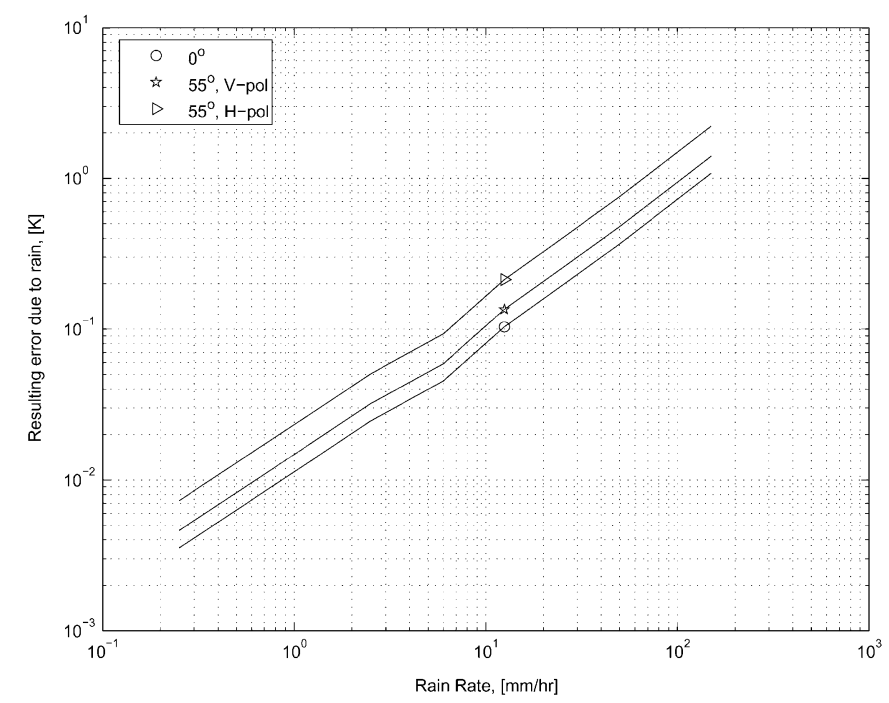

Fig. 6. Resulting difference between the brightness temperature measured by the radiometer and the emitted sea surface brightness temperature for a surface air temperature of $293 \mathrm{~K}$. The resulting error is shown for three different incidence angles. The rain is assumed to be located in the lower $2 \mathrm{~km}$ of the atmosphere.

To find the impact of the attenuation coefficient due to rain, an example has been evaluated. In this example, it is assumed that the rain is located in the lower $2 \mathrm{~km}$ of the atmosphere, and the atmospheric loss and the resulting error has been calculated the same way as done in the previous sections. The outcome concerning the resulting error is seen in Fig. 6, as usual for two different incidence angles. It is seen that the influence of rain can be neglected for rain rates lower than some $10 \mathrm{~mm} / \mathrm{h}$.

Higher rain rates (more than $10 \mathrm{~mm} / \mathrm{h}$ ), which are most likely to occur in the equatorial area, have to be taken into consideration. The question now is: how often does a situation like this actually occur over areas comparable with the SMOS footprint? In order to investigate this, we have used global rain rates obtained from the Special Sensor Microwave Imager (SSM/I). The SSM/I instrument is operated in a near-polar orbit and has a daily coverage of almost the entire Earth. The data, used here, are resampled in a $25-\mathrm{km}$ grid, so the resolution of the rain rates obtained is $25 \mathrm{~km}$. In order to find an estimate of the global percentage 
TABLE VII

Average Percent of the Sea Surface Area, Which Is Covered by a Rain Rate of $10 \mathrm{~mm} / \mathrm{h}$ OR More. The Percentage RaIn Coverage Has BeEn Calculated From SSM/I Data. The Data InCluded Are OBTAINED THE 1ST AND THE 15TH IN EACH MONTH OF 2003

\begin{tabular}{l|c|c|c|c}
\hline & \multicolumn{2}{|c|}{ Ascending Orbit } & \multicolumn{2}{c}{ Descending Orbit } \\
\hline & 1 st & 15 th & 1 st & 15 th \\
\hline January & $0.2294 \%$ & $0.2461 \%$ & $0.2330 \%$ & $0.1895 \%$ \\
February & $0.2442 \%$ & $0.1862 \%$ & $0.2894 \%$ & $0.0827 \%$ \\
March & $0.3113 \%$ & $0.1562 \%$ & $0.1891 \%$ & $0.1336 \%$ \\
April & $0.2705 \%$ & $0.2028 \%$ & $0.1460 \%$ & $0.1531 \%$ \\
May & $0.2711 \%$ & $0.1959 \%$ & $0.1595 \%$ & $0.1424 \%$ \\
June & $0.1964 \%$ & $0.2525 \%$ & $0.1514 \%$ & $0.1280 \%$ \\
July & $0.1612 \%$ & $0.3869 \%$ & $0.1059 \%$ & $0.3010 \%$ \\
August & $0.3280 \%$ & $0.2039 \%$ & $0.2039 \%$ & $0.1750 \%$ \\
September & $0.3303 \%$ & $0.1788 \%$ & $0.1599 \%$ & $0.0953 \%$ \\
October & $0.2663 \%$ & $0.2783 \%$ & $0.1420 \%$ & $0.1486 \%$ \\
November & $0.1838 \%$ & $0.2893 \%$ & $0.1239 \%$ & $0.2560 \%$ \\
December & $0.2713 \%$ & $0.3620 \%$ & $0.1743 \%$ & $0.1345 \%$ \\
\hline Average & $0.2553 \%$ & $0.2449 \%$ & $0.1732 \%$ & $0.1616 \%$ \\
\hline
\end{tabular}

area covered by rain rates of $10 \mathrm{~mm} / \mathrm{h}$ or more, we have used rain rate data for the 1 st and the 15 th in each month of 2003 . For each day, the rain rates are calculated for the ascending and descending orbits by the company Remote Sensing Systems using an algorithm described in [16]. From these datasets, we have calculated how much of the area covered by the SSM/I instrument is covered by rain rates of $10 \mathrm{~mm} / \mathrm{h}$ or more, and this is assumed to be a good estimate for the global situation. The result of the investigation can be seen in Table VII.

The percentage has been calculated both for the ascending and the descending orbits in order to reveal possible differences related to time of day. When looking at the results, it can be seen that the problem with rain rates of $10 \mathrm{~mm} / \mathrm{h}$ or more only occur approximately $0.2 \%$ of the time, and this is so seldom that it probably can be neglected. But, high rain rates might still be a problem if they always occur in specific areas. In order to investigate this issue a little further, the average percent rain rate of $10 \mathrm{~mm} / \mathrm{h}$ or more has been calculated in the area around the equator $\left(10^{\circ} \mathrm{N}\right.$ to $10^{\circ} \mathrm{S}$ ). The result can be seen in Table VIII. From this table, it can be seen that even in areas where it rains more than average the problem only occurs approximately $0.65 \%$ of the time.

Finally, it must be noted that these considerations are actually conservative, as they deal with $25-\mathrm{km}$ grid cells and SMOS uses $50-\mathrm{km}$ cells. In conclusion: rain will in general not have a significant influence on remote sensing of the sea surface brightness temperature at L-band.

\section{DISCUSSION AND CONCLUSION}

A detailed analysis of various atmospheric error sources that influence the microwave remote sensing of the ocean surface salinity at $1.4 \mathrm{GHz}$ has been carried out. Some of them are shown to have an influence, which is not negligible compared with the accuracy required for that task. In all cases the influence is compared with a $0.1 \mathrm{~K}$ accuracy level. This is to be understood the way that if the influence is below $0.1 \mathrm{~K}$ it may be disregarded, if it is larger, it must be corrected for, and this correction must achieve a final accuracy better than $0.1 \mathrm{~K}$. The required knowledge of relevant geophysical parameters is stated. Of course a different level than $0.1 \mathrm{~K}$ may be necessary-e.g., in the case where several independent errors are present and the total accuracy is still wanted to be better than $0.1 \mathrm{~K}$. In most cases the present results can be scaled accordingly.
TABLE VIII

Average Percent of the Sea Surface Area Around Equator $\left(10^{\circ} \mathrm{N}\right.$ TO $\left.10^{\circ} \mathrm{S}\right)$, WHICH IS COVERED BY A RAIN RATE OF $10 \mathrm{~mm} / \mathrm{h}$ or More. The Percent Rain Coverage Has Been Calculated From SSM/I DATA. THE DATA INCLUdEd ARE OBTAINED ThE 1ST AND THE 15TH IN EACH MONTH OF 2003

\begin{tabular}{l|c|c|c|c}
\hline & \multicolumn{2}{|c|}{ Ascending Orbit } & \multicolumn{2}{c}{ Descending Orbit } \\
\hline & 1 st & 15 th & 1 st & 15 th \\
\hline January & $0,9531 \%$ & $0,7378 \%$ & $1,0025 \%$ & $0,3785 \%$ \\
February & $1,3341 \%$ & $0,4754 \%$ & $1,4342 \%$ & $0,2337 \%$ \\
March & $0,7408 \%$ & $0,3858 \%$ & $0,7213 \%$ & $0,3259 \%$ \\
April & $1,1756 \%$ & $0,6460 \%$ & $0,4452 \%$ & $0,2330 \%$ \\
May & $0,8670 \%$ & $0,8263 \%$ & $0,5649 \%$ & $0,5597 \%$ \\
June & $0,5688 \%$ & $0,8716 \%$ & $0,2200 \%$ & $0,3199 \%$ \\
July & $0,4434 \%$ & $0,9290 \%$ & $0,5687 \%$ & $0,6310 \%$ \\
August & $0,8980 \%$ & $0,5891 \%$ & $0,8592 \%$ & $0,7888 \%$ \\
September & $0,6352 \%$ & $0,2697 \%$ & $0,2513 \%$ & $0,1726 \%$ \\
October & $1,1145 \%$ & $0,5614 \%$ & $0,4901 \%$ & $0,2203 \%$ \\
November & $0,6983 \%$ & $0,8070 \%$ & $0,2411 \%$ & $0,9233 \%$ \\
December & $0,5512 \%$ & $1,5633 \%$ & $0,2174 \%$ & $0,5387 \%$ \\
\hline Average & $0,8317 \%$ & $0,7219 \%$ & $0,5847 \%$ & $0,4438 \%$ \\
\hline
\end{tabular}

Concerning oxygen, the investigation finds a significant influence, and therefore oxygen loss is a factor, which needs to be corrected for. This can be done in a rather simple way, but in order to be able to do it, knowledge of the physical air temperature and pressure is needed. The vertical polarization brightness temperature can be corrected to better than $0.1 \mathrm{~K}$ provided the temperature is known to within $7{ }^{\circ} \mathrm{C}$ and the pressure is known to within $14 \mathrm{mb}$. These are not stringent requirements. The horizontal polarization signal at high incidence angle is slightly more sensitive to the losses, and at $55^{\circ}$ incidence the temperature must be known to within $3{ }^{\circ} \mathrm{C}$ and the pressure to within $8 \mathrm{mb}$ in order to obtain an accuracy of $0.1 \mathrm{~K}$. But recall that this is the extreme situation, and for moderate incidence angles numbers approach the vertical polarization values.

Concerning the influence of water vapor, the investigations show that it is so small (except for extreme mass densities of the water vapor), that it can generally be neglected. If required-e.g., in equatorial regions-a correction for water vapor can be done, and it requires knowledge of the physical air temperature, pressure, and mass density of the water vapor. The requirements to know these geophysical parameters are quite modest because the brightness temperature is only weakly dependent on water vapor loss.

When considering the influence of clouds on the electromagnetic radiation it is in principle somewhat more complicated. This is due to the fact that a cloud is more complicated to describe than oxygen or water vapor. Clouds have highly variable features. A cloud is characterized by properties such as the base of the cloud, the top of the cloud, and the physical content of the cloud. All these properties have an influence on the cloud's interference with the electromagnetic radiation. Some simulations for different standard types of clouds have been carried out, and it is seen that in general the influence from clouds can be neglected. Only in extreme cases at low temperatures, significant cloud effects are noted, but this happens rarely and anyhow probably not with $100 \%$ coverage within the radiometer footprint.

The influence of rain on the propagation of the electromagnetic waves has also been investigated. The conclusion of the investigation is that rain rates of less than $10 \mathrm{~mm} / \mathrm{h}$, do not affect the propagation, but rain rates above this do have an effect. Therefore, an investigation, based on SSM/I satellite data, has 
been carried out on how often rain rates like this occur. Such rain rates occur less than $0.2 \%$ of the time over a $25-\mathrm{km}$ grid cell, and therefore the interference from rain is generally not significant. In areas where larger than average rain rates are likely to occur (in the equatorial areas), the situation has been further considered, and it is found that the problem only appears approximately $0.65 \%$ of the time. Furthermore, it is noted that the present investigation concerns a $25-\mathrm{km}$ cell size, so over the larger SMOS footprint, the occurrence of more than $10 \mathrm{~mm} / \mathrm{h}$ rain will be even rarer. In short: rain will in general not play a significant role for the $1.4-\mathrm{GHz}$ radiometric measurements.

It is worth noticing that setting a $0.1-\mathrm{K}$ limit as to the acceptable influence is actually on the conservative side. For practical spaceborne radiometer systems, it is necessary to carry out integration in time and space (several footprints or orbits averaged) to achieve the radiometric sensitivity and accuracy required to do proper salinity measurements. Hence, the influence of clouds and rain on the final result is further reduced by this integration. And likewise, the requirements to know the geophysical parameters in order to compensate for oxygen and water vapor absorption are reduced.

It is noted that in order to perform a correction for oxygen losses, knowledge of air temperature and pressure in the lower $30 \mathrm{~km}$ of the atmosphere is required (if a correction for water vapor losses is deemed necessary, an approximate knowledge of vapor mass density is also required). These geophysical parameters must be known with better accuracy than what is possible using the 1962 U.S. Standard Atmosphere and surface measurements: proper three-dimensional measurements/models must be used. Such data are available, for example, from the European Centre for Medium-Range Weather Forecasts (see www.ecmwf.int).

Finally, it must be recalled that the estimates of the quite important oxygen loss are based on a certain model for the atmospheric loss as a function of frequency, temperature, and air density. Several models exist, and there are small differences between them: some are claimed to be better at for example certain frequency intervals than others. It is fair to state that all models focus on much higher frequencies than L-band. Additionally, all models are supported by physical measurements of a certain accuracy. For example, a case from literature can be mentioned in which a model output for total zenith opacity (L-band) of 0.030 $\mathrm{dB}$ is compared with a measured value of $0.034 \mathrm{~dB}$ that has a $\pm 0.008-d B$ accuracy! Another example is the range of published values for $\gamma_{0}$ in (6) and (7): here is used 0.59, in [17] 0.49 , in [18] 0.54, and finally in [19] 0.57. Thus, it is questionable if the existing models really can be exploited to the level of detail required for the present task where high-fidelity compensation for oxygen effects shall be carried out (even assuming perfect knowledge of temperature and pressure profiles). Possibly the upcoming L-band missions might lead to improved models for the oxygen influence on L-band radiometry through multiparameter regressions of brightness temperatures and atmospheric parameters.

\section{ACKNOWLEDGMENT}

Discussions with the SMOS team has been very helpful. The very thorough and productive work of the reviewers is highly appreciated.

\section{REFERENCES}

[1] S. H. Yueh, R. West, W. J. Wilson, F. K. Li, E. G. Njoku, and Y. RahmatSamii, "Error sources and feasibility for microwave remote sensing of ocean surface salinity," IEEE Trans. Geosci. Remote Sens., vol. 39, no. 5, pp. 1049-1059, May 2001.

[2] D. M. Le Vine and S. Abraham, "The effect of the ionosphere on remote sensing of sea surface salinity from space: Absorption and emission at L band,' IEEE Trans. Geosci. Remote Sens., vol. 40, no. 4, pp. 771-782, Apr. 2002.

[3] N. Skou, "Faraday rotation and L band oceanographic measurements," Radio Sci., vol. 38, no. 4, p. 8, Jul.-Aug. 2003.

[4] R. K. Crane, "Propagation phenomena affecting satellite communication systems operating in the centimeter and millimeter wavelength bands,' Proc. IEEE, vol. 59, no. 2, pp. 173-188, Feb. 1971.

[5] F. T. Ulaby, R. K. Moore, and A. K. Fung, Microwave Remote Sensing-Active and Passive. Norwood, MA: Artech House, 1981, vol. 1.

[6] L. A. Klein and C. T. Swift, "An improved model for the dielectric constant of sea water at microwave frequencies," IEEE Trans. Antennas Propagat., vol. AP-25, no. 1, pp. 104-111, Jan. 1977.

[7] H. J. Liebe, G. A. Hufford, and M. G. Cotton, "Propagation modeling of moist air and suspended water/ ice particles at frequencies below 1000 GHz," presented at the AGARD 52nd Specialists Meeting of the Electromagnetic Wave Propagation Panel, Palma de Mallorca, Spain, 1993.

[8] P. W. Rosenkrantz, "Interference coefficients for overlapping oxygen lines in air," J. Quant. Spectrosc. Radiat. Transf., vol. 39, pp. 287-297, 1988.

[9] P. W. Rosenkrantz, "Absorption of microwaves by atmospheric gasses," in Atmospheric Remote Sensing by Microwave Radiometry, M. A. Janssen, Ed. New York: Wiley, 1993, pp. 37-79.

[10] P. W. Rosenkrantz, "Water vapor microwave continuum absorption: A comparison of measurements and models," Radio Sci., vol. 33, no. 4, pp. 919-928, Jul.-Aug. 1998.

[11] J. W. Waters, "Absorption and emission of microwave radiation by atmospheric gases," in Methods of Experimental Physics, 12th ed, M. L. Meeks, Ed. Orlando, FL: Academic, 1976, pt. B, Radio Astronomy .

[12] K. S. Fraser, N. E. Gaut, E. C. Reifenstein, and H. Sievering, "Interaction mechanisms within the atmosphere," in Manual of Remote Sensing, R. G. Reeves, Ed. Falls Church, VA: Amer. Soc. Photogramm., 1975, vol I, pp. 207-210.

[13] J. F. R. McIlveen, Basic Meteorology, a Physical Outline. Berkshire, U.K.: Van Nostrand Reinhold, 1986, p. 457.

[14] A. Benoit, "Signal attenuation due to neutral oxygen and water vapor, rain, and clouds," Microw. J., vol. 11, pp. 73-80, 1968.

[15] D. E. Setzer, "Computed transmission through rain at microwave and visible frequencies," Bell Syst. Tech. J, Oct. 1970.

[16] F. Wentz, "A well-calibrated ocean algorithm for Special Sensor Microwave/Imager,” J. Geophys. Res., vol. 102, pp. 8703-8718, 1997.

[17] P. W. Rosenkranz, "Shape of the $5 \mathrm{~mm}$ oxygen band in the atmosphere," IEEE Trans. Antennas Propagat., vol. AP-23, pp. 498-506, 1975.

[18] R. G. Gordon, "On the pressure broadening of molecular multiplet spectra," J. Chem. Phys., vol. 40, pp. 448-455, 1967.

[19] H. J. Liebe, "An updated model for millimeter wave propagation in moist air,” Radio Sci., vol. 20, pp. 1069-1089, 1985.

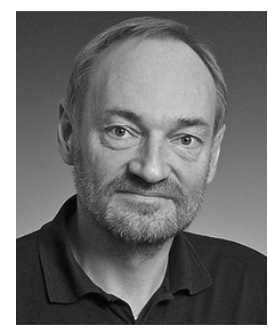

Niels Skou (S'78-M'79-SM'96-F'03) received the M.Sc., Ph.D., and D.Sc. degrees from the Technical University of Denmark (DTU), Lyngby, in 1972 , 1981, and 1990, respectively.

$\mathrm{He}$ is currently a Professor with DTU. His research has been directed toward microwave remote sensing systems. After working for three years with the development of radar systems for measuring the ice sheets in Greenland and Antarctica, his interest turned toward microwave radiometry. He developed a scanning, multifrequency, airborne radiometer system. After that, his subjects were radiometer measurements of sea ice and oil pollution on the sea, spaceborne radiometer systems, and development of new systems for specific purposes. In the mid-1980s, his interest turned back to active instruments, and he became engaged in the development of an airborne, multifrequency, polarimetric, and interferometric synthetic aperture radar system-with special emphasis on calibration fidelity. However, activity within microwave radiometry has continued, mainly within the areas of synthetic aperture radiometry and polarimetric radiometry. The work on synthetic aperture radiometry has led to the Soil Moisture and Ocean Salinity (SMOS) mission, one of ESA's Earth Explorer Opportunity Missions, and he is currently heavily involved in this project, e.g., as a member of the SMOS Science Advisory Group.

Dorthe Hoffman-Bang, photograph and biography not available at the time of publication. 